\title{
Respiratory System Findings Planned End of Assessment Interval
}

National Cancer Institute

\section{Source}

National Cancer Institute. Respiratory System Findings Planned End of Assessment

Interval. NCI Thesaurus. Code C123964.

The period of time that the respiratory system assessment, done over an interval of time, is intended to finish. 